\title{
LABIAL FUSION CAUSING UPPER URINARY TRACT OBSTRUCTION
}

\author{
JOHN C. NORBECK, M.D. \\ MICHAEL R. RITCHEY, M.D. \\ DAVID A. BLOOM, M.D.
}

\author{
From the Section of Urology, University of Michigan \\ Medical Center, Ann Arbor, Michigan
}

\begin{abstract}
An infant with dense and nearly complete labial fusion had marked hydroureteronephrosis which resolved after incision of the adherent labia. Although this is an unusual consequence of labial fusion, it argues for upper urinary tract screening in these children.
\end{abstract}

Under the title "Atresia of the Vulva in Children," Nowlin and Adams ${ }^{1}$ presented the first detailed report of labial adhesions in the American literature in 1936. Campbell ${ }^{2}$ used the term vulvar fusion and provided a comprehensive review of 9 cases in 1940 . Only 29 cases were reported by 1949. 'The urinary tract is rarely investigated in children with labial adhesions. We report a case of labial fusion that resulted in marked hydronephrosis.

\section{CASE REPORT}

A six-month-old female baby was hospitalized for a febrile urinary tract infection. Renal ultrasonography revealed a very large capacity bladder and marked bilateral hydroureteronephrosis (Fig. 1). An intravenous urogram (IVU) demonstrated poor excretion of contrast material bilaterally. A voiding cystourethrogram (VCUG) could not be performed due to inability to catheterize the urethra. The child was subsequently evaluated in our clinic.

She was an afebrile and healthy-appearing infant with dense and nearly complete fusion of the labia minora (Fig. 2). The adhesions were incised under anesthesia. A small lacrimal probe was all that could be introduced through the labial opening. The synechiae vulva were divided. Introital anatomy was otherwise normal. Cystoscopy demonstrated a large bladder with lateral ureteral orifices of golf-hole configuration. Following surgery, VCUG showed grade 5/5 left vesico-

Submitted: March 9, 1993, accepted: March 12, 1993 ureteral reflux. On diuretic renography, the $t^{1 / 2}$ times were prolonged bilaterally but both sides responded to furosemide. Differential function was 51 percent on the right and 49 percent on the left. The patient was placed on a regimen of suppressive antibiotics and given estrogen cream for topical labial application.

Renal ultrasonography three weeks later revealed complete resolution of the hydronephrosis, normal renal echotexture, and a normal bladder (Fig. 3). An IVU showed prompt symmetric function and a normal collecting system. The $\mathrm{t}^{1 / 2}$ normalized bilaterally on diuretic renogram. A follow-up VCUG demonstrated bilateral grade 5/5 vesicoureteral reflux with prompt drainage and no persistent dilatation.

\section{COMMENT}

This clinical entity has been called labial adhesion, labial fusion, adhesive vulvitis, interlabial occlusion of the vulva, synechia vulvae, vulvar adhesion, vulvar fusion, and vulvar atresia although the actual site of fusion is the labia minora. ${ }^{3} \mathrm{Con}$ troversy exists as to whether this condition is congenital or acquired. The labia minora form from the genital folds which in turn develop from the lips of a groove on the genital tubercle. Campbell ${ }^{2}$ postulated that adhesion of the labia minora has an embryologic basis, and believed that it is the result of midline fusion of the labioscrotal folds. In contrast, Nowlin and Adams ${ }^{1}$ emphasized that at no time in normal female development is there fusion of the genital folds, therefore adhesion of the vulva is unlikely the product of abnormal 


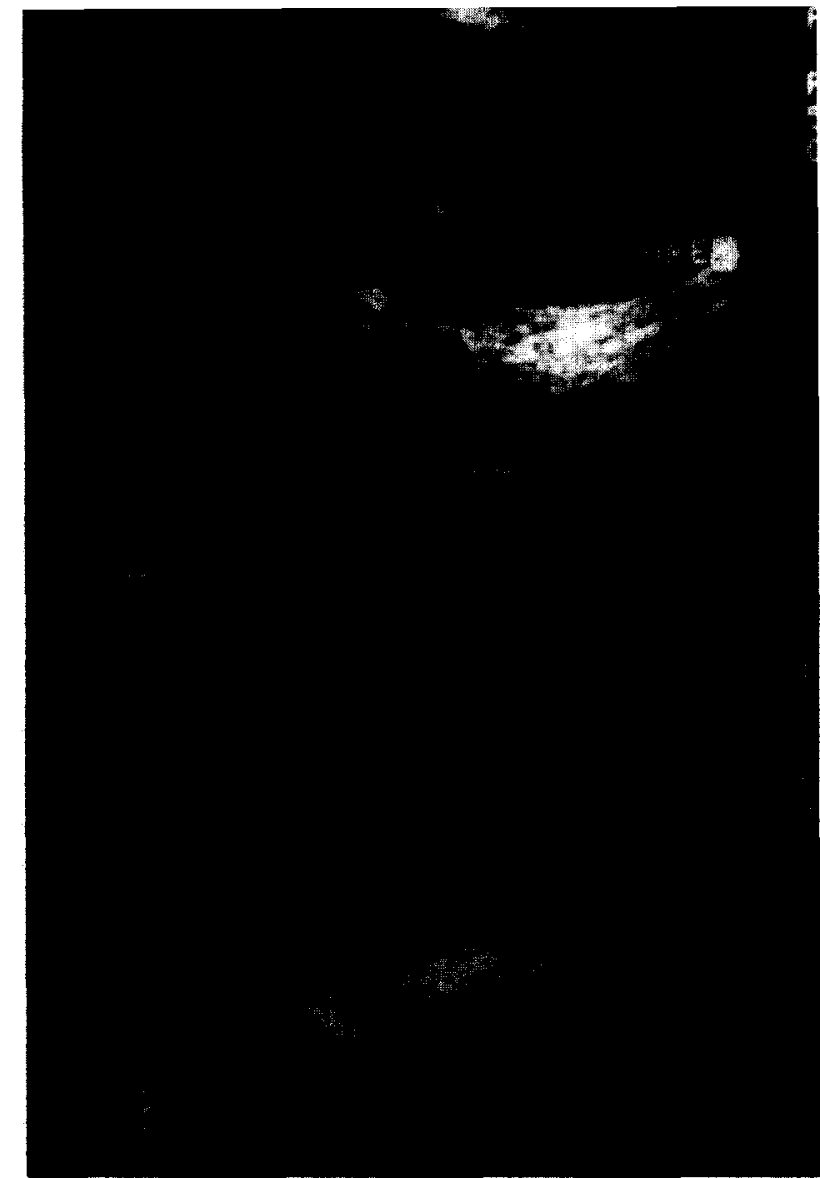

FIGURE 1. (A) Preoperative renal ultrasound showing marked hydroureteronephrosis. (B) Preoperative transverse ultrasound of pelvis demonstrating bilateral ureteral dilation (arrows).

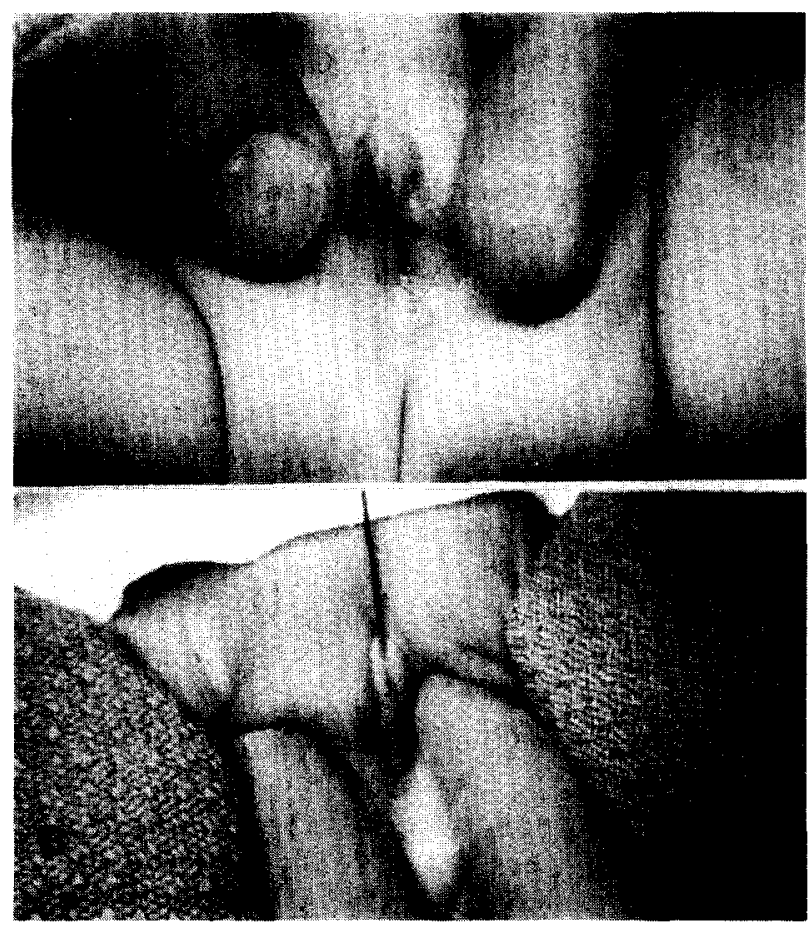

FIGURE 2. (A) Intraoperative photograph showing labial fusion and no visible opening for urination. (B) Intraoperative view of lacrimal probe in 1-mm opening located just beneath clitoris.

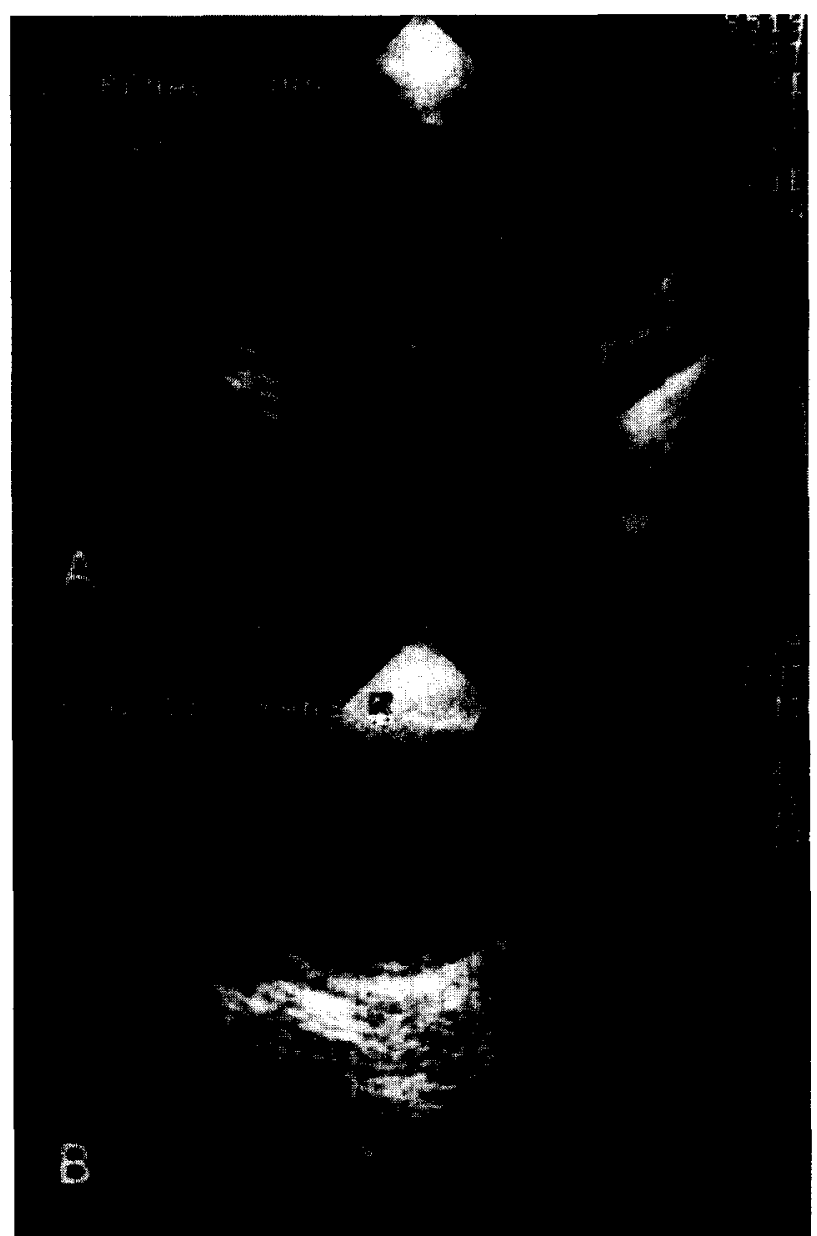

FIGURE 3. (A) Renal ultrasound three weeks after incision of labial fusion demonstrating normal echotex ture and no collecting system dilation. (B) Ultrasound of pelvis three weeks after incision demonstrating resolution of ureteral dilation.

development. Vakar ${ }^{4}$ believed that the physiologic desquamative vulvovaginitis of the newborn caused labial fusion permitting penetration of pathogens that in turn is followed by infection and adhesion.

The labia minora in infants and young girls has abundant vascularity and cellularity. At the most posterior portion of the introitus, the labia are in very close proximity. Mild inflammation may easily result in labial agglutination without marked vulvitis. The exact incidence of labial fusion is unknown. In reviewing our own experience in Ann Arbor, 11 cases have been treated among 2,000 consecutive new female patient visits. This may underrepresent the true incidence as many of these patients may be managed without referral to a urology clinic.

Gentle labial separation reveals a thin bluish semi-transparent membrane to dense fusion with only a small pinpoint opening just below the clitoris. This membrane often bulges with urination. 
The opening is posterior to the clitoris but anterior to the urethral meatus, so that a diaphragm interferes with bladder emptying. Urinary tract symptoms have been described in 20-38 percent of labial fusion patients. ${ }^{1,5}$ Other presentations include lower abdominal pain ${ }^{6}$ history of perineal trauma, ${ }^{7}$ or abnormal physical findings by parents or physician.

Campbell's patients were originally thought to have pseudohermaphroditism. ${ }^{2}$ Treatment requires separation of the midline fusion. Campbell inserted a hemostat into the small orifice below the clitoris and then opened it widely to bluntly separate the labia. He believed that preputial adhesions to clitoris should be separated for fear that retained smegmatic debris induced masturbation. ${ }^{2}$ Nowlin and Adams ${ }^{1}$ recommended simple separation of the labia minor and application of a bland ointment to the raw edges. Huffman ${ }^{8}$ advised topical application of estrogen cream rather than direct separation. Capraro and Greenberg, ${ }^{5}$ after high failure rates with blunt separation, reported separation after two to four weeks of estrogen cream. Anderson ${ }^{9}$ recommended no treatment unless urinary tract symptoms coexisted. We believe that filmy asymptomatic labial fusion can be treated with a limited course of estrogen cream, but recurrence, dense adherence, or symptomatic labial fusion is best managed by operative incision with cystourethroscopy and vaginoscopy. Postoperatively, application of estrogen cream is continued twice daily for two weeks.

In most published series of children with labial fusion the upper urinary tracts were not evaluated. Only 1 of 9 patients in Campbell's ${ }^{2}$ report had upper tract evaluation and that was normal. Taylor ${ }^{7}$ described " 2 cases with urological aspects" but neither case had upper tract investigation. Similarly, Nowlin and Adams ${ }^{1}$ did not perform radiographic imaging in 110 patients with labial adhesion. The massive hydroureteronephrosis of the patient herein reported resolved completely with incision of the labial fusion. This suggests that the findings were not due entirely to primary reflux but were the result of bladder outlet obstruction secondary to the labial fusion. Children with dense fusion and small introital apertures may be more susceptible to obstructive changes. Ultrasonography is suggested in these instances of labial fusion.

$$
\begin{array}{r}
\text { John Norbeck, M.D. } \\
\text { Madigan Army Medical Center } \\
\text { Urology Service } \\
\text { Box } 310801
\end{array}
$$

Tacoma, Washington 98431-5302

\section{REFERENCES}

1. Nowlin P, and Adams JR: Cited in Nowlin P, Adams JR, and Nalle BC Jr: Vulvar fusion. J Urol 62: 75-79, 1949.

2. Campbell MF: Vulvar fusion. JAMA 115: 513-515, 1940.

3. Bowles HE, and Childs LS: Synechias of vulva in small children. AJDC 66: 258-263, 1943.

4. Vakar NA: Adhesions of vulvar in young children. Pediatriya 14: 477-482, 1930.

5. Capraro VJ, and Greenberg H: Adhesions of the labia minora. A study of 50 patients. Obstet Gynecol 39: 65-69, 1972.

6. Glenn JF: Labial fusion and urinary infection. J Urol 87: 485-486, 1962.

7. Taylor WN: Vulvar fusion: two cases with urological aspects. J Urol 45: 710-714, 1941.

8. Huffulan JW: The Gynecology of Childhood and Adolescence. Philadelphia, WB Saunders Saunders Company, 1968, p 125.

9. Anderson OW: Treatment of labial adhesions in children. JAMA 162: 951-953, 1956. 